NOTE

\title{
Nesting phenologies of two sympatric sea turtle species related to sea surface temperatures
}

\author{
John F. Weishampel*, Dean A. Bagley, Llewellyn M. Ehrhart, \\ Anthony C. Weishampel \\ Department of Biology, University of Central Florida, Orlando, Florida 32816, USA
}

\begin{abstract}
As ectotherms, sea turtles are particularly sensitive to ambient temperature. Because of their charismatic megafauna and imperiled status, there is considerable interest as to how species in this taxon have responded to recent ocean warming and may respond to predicted warming trends. The fact that they are wide-ranging and evolutionarily ancient organisms suggests that marine turtles withstood changing climatic conditions in the past. To test if there are thermal cues that relate to dynamic nesting behaviours of loggerheads Caretta caretta and green turtles Chelonia mydas, we examined 20 yr (1989-2008) data sets of beach monitoring surveys and satellite-derived sea surface temperature (SST) from an important nesting site in east central Florida, USA, and adjacent Atlantic waters, respectively. For both species, median nesting dates became significantly earlier with higher May SSTs. However, the standard deviation of nest distributions, used as an analog for nesting season length, decreased for loggerheads and, in contrast, increased for green turtles with a higher average daily SST. This differential response between the species may reflect changes in reproductive physiology (e.g. internesting interval times and clutch numbers) and could have bearing on the future population dynamics of the 2 species.
\end{abstract}

KEY WORDS: Caretta caretta · Chelonia mydas · Florida · Global warming · Oviposition · Thermal habitat

\section{INTRODUCTION}

Understanding how endangered species are responding to present and will respond to future climate change is critical for determining population vulnerability (Williams et al. 2008) and whether or not altering management and/or monitoring strategies is warranted. However, as climatic changes vary geographically and as species responses to similar climate shifts are often different (Parmesan 2006), trying to predict responses for broadly distributed, wide-ranging species is not trivial. The complex life history and migratory patterns of sea turtles have been shown to be linked closely with ocean temperatures (e.g. Coles \& Musick 2000, Mazaris et al. 2004, Hawkes et al. 2007a, Poloczanska et al. 2009). As a result, several empirical and theoretical studies (reviewed by Hawkes et al. 2009) have begun to explore the effects of recent climate change and the ramifications of future warming on the behavioural, physiological, and population dynamics of these ectothermic megafauna.

Sea turtles have shown species- and/or geographically specific temperature-related phenological migratory and nesting responses (Weishampel et al. 2004, Pike et al. 2006, Hawkes et al. 2007b, Mazaris et al. 2008, Pike 2009). Within a season, internesting interval length is related to the thermal environments (Sato et al. 1998, Hays et al. 2002, Cheng et al. 2009). Though sea turtles possess a high degree of nest site fidelity, their proclivity to track thermal habitats at macro- (e.g. Seminoff et al. 2008) and micro- (Schofield et al. 2009) scales influences their energy budgets, which in turn may affect the tim- 
ing of courtship (Hamann et al. 2003) and nesting behaviours. Thus, ambient temperatures associated with their swimway (migratory) and local (internesting) movements may contribute to variability in the initiation and duration of nesting. Furthermore, because sea turtles are capital breeders (Bonnet et al. 1998) and often forage and nest in different areas, the climate of the foraging grounds, which may be hundreds or thousands of kilometers away, can influence their reproductive physiology and the onset of migration. These geographic complications make it difficult to determine the broad implications of global warming on sea turtle nesting based on a few, relatively short-term studies (Hawkes et al. 2009, Poloczanska et al. 2009).

The subtropical beaches of east central Florida, USA, represent important rookeries for 2 marine turtle species, loggerheads Caretta caretta and green turtles Chelonia mydas. Presently, the nest numbers of these 2 species are undergoing different trajectories. Loggerhead turtle nests are experiencing a decline (Witherington et al. 2009), while green turtle nests are on the rise (Chaloupka et al. 2008a). In a previous, $15 \mathrm{yr}$ study of the temporal nesting patterns of loggerhead turtles on these beaches (Weishampel et al. 2004), it was found that the median day of nesting had become earlier in relation to sea surface warming. Because of the relatively low numbers of green turtle nests over that 1989-2003 period, compared to loggerhead nests, we did not analyze their nesting phenology. However, green turtle nest numbers on these beaches have tripled over the last decade, increasing at a rate higher than any other large rookery (Chaloupka et al. 2008a), and now are thought to be sufficient for a similar analysis.

Though the 2 species are morphologically comparable, use similar nesting habitats, and exhibit analogous migratory and nesting behaviours (as outlined in Pike 2009), given their difference in trophic levels - green turtles feed at 2 to 3 trophic levels below loggerheads (Godley et al. 1998) - there is little reason to assume that their responses to warming trends will be the same (Edwards \& Richardson 2004, Visser \& Both 2005). Here we follow-up our previous study (Weishampel et al. 2004) of temporal nesting patterns of loggerhead turtles in relation to sea surface warming on an important subtropical Atlantic nesting beach. We extended our previous analysis by $5 \mathrm{yr}$ and included an analysis of green turtle nesting activity in the study area.

\section{MATERIALS AND METHODS}

Study area. The $40.5 \mathrm{~km}$ stretch of beach is on a barrier island extending northward from Sebastian Inlet $\left(27.86^{\circ} \mathrm{N}, 80.45^{\circ} \mathrm{W}\right)$ to Patrick Air Force Base on the east central coast of Florida (Fig. 1). It is home to the highest nest densities of loggerheads in the western hemisphere and green turtles in the continental United States (Ehrhart et al. 2003, USFWS 2009). This beach has varying degrees of coastal development ranging from dense condominiums to the north to less dense, single family homes to the south; the southern $20.5 \mathrm{~km}$ is home to the Brevard County portion of the Archie Carr National Wildlife Refuge. For loggerheads, this stretch corresponds roughly to the latitudinal middle of their western North Atlantic nesting beaches (Ehrhart et al. 2003) and accounts for $\sim 30 \%$ of nesting in the United States (USFWS 2009). For green turtles, this stretch represents the northernmost large nesting area in the western North Atlantic (CCC 2009) and accounts for $30 \%$ of nesting in the continental United States (B. Witherington pers. comm.). Loggerheads and green turtles nest sporadically as far north as Virginia $\left(\sim 37.5^{\circ} \mathrm{N}\right)$ and North Carolina $\left(\sim 35.5^{\circ} \mathrm{N}\right)$, respectively (Schwartz et al. 1981, Woodson \& Webster 1999, Cross et al. 2001).

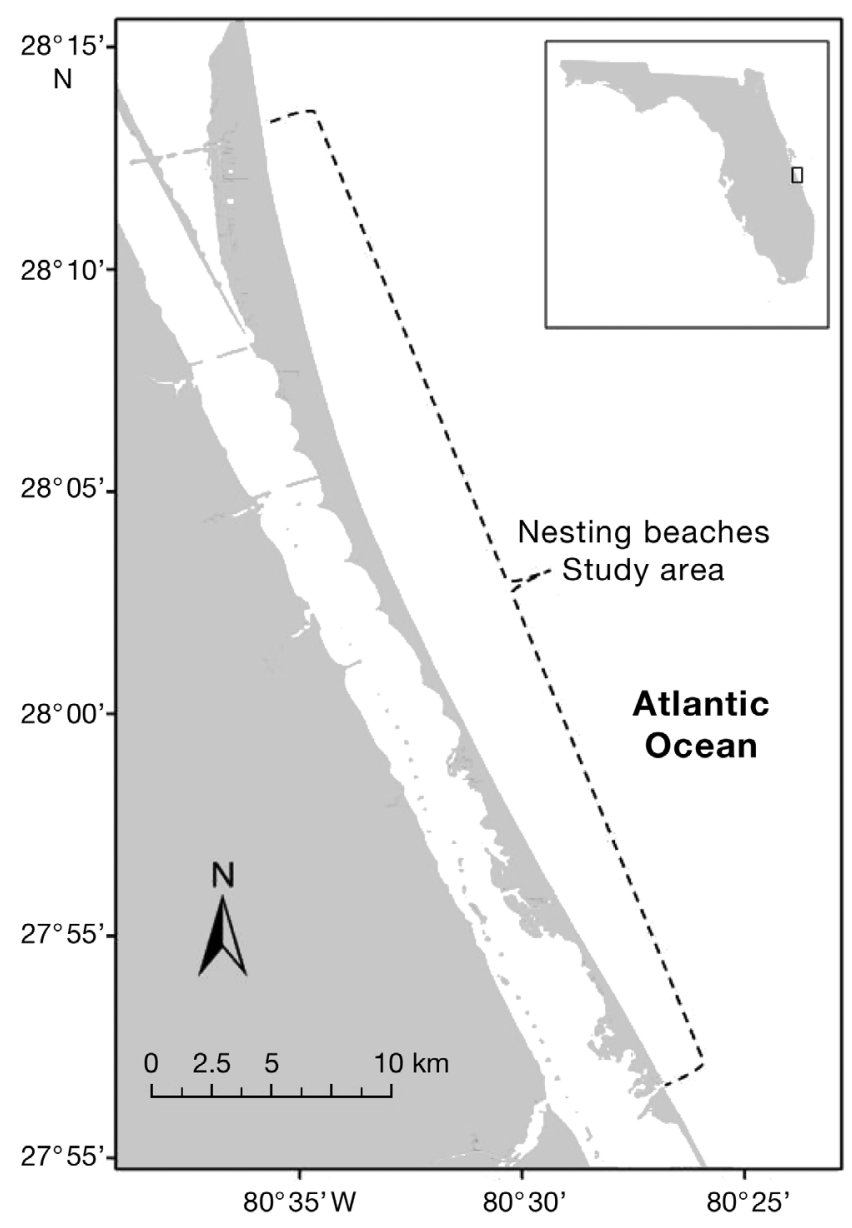

Fig. 1. Study area along the east coast of central Florida, USA (inset). Extent of the $40.5 \mathrm{~km}$ beach stretch is designated by the dashed bracket 
Field sampling. Since 1989, the University of Central Florida (UCF) Marine Turtle Research Group has monitored nesting and reproductive success on these critical beaches following the Index Nesting Beach Survey (INBS) program developed by the Florida Fish and Wildlife Conservation Commission (FWRI 2009). These protocols permit comparisons among INBS beaches across the state of Florida and the tracking of long-term trends since their establishment in 1989. Although INBS standardized methods were applied, the length of the UCF monitoring season increased over the $20 \mathrm{yr}$ period, beginning as early as mid-February and ending as late as November. To maintain a consistent sampling effort, we examined a window of daily nest surveys from 10 May to 31 August. This window was sampled each day and encompasses the vast majority of loggerhead $(98.2 \%)$ and green turtle $(93.4 \%)$ nests recorded on these beaches; nevertheless, it tends to exclude some early nesting loggerheads and late nesting green turtles as well as the occasional late nesting loggerhead (Weishampel et al. 2006). We only analyzed nesting emergences for which a clutch was laid.

Sea surface temperature (SST) data. We acquired SST measurements from the Physical Oceanography Distributed Active Archive Center (PODAAC) at the NASA Jet Propulsion Laboratory (JPL). These SST values, derived in situ (buoy) and remotely by the NOAA Advanced Very High Resolution Radiometer (AVHRR) satellite sensors, have been calculated and archived since 1981. Monthly SST data (Reynolds \& Smith 1994 ) at a $1^{\circ} \times 1^{\circ}$ resolution for the Atlantic Ocean region adjacent to the nesting beaches were downloaded using the PODAAC Ocean Earth Science Information Partner Tool (POET) for 1989 to 2008.

Data analysis. Using ordinal dates weighted by nest number, we characterized loggerhead and green turtle nesting frequency distributions using standard statistical descriptors (e.g. mean, median, standard deviation, skewness, and kurtosis) within the 10 May to 31 August monitoring time frame for each year. The use of standard deviation as a measure of dispersion of the nesting season is more robust than using the first and the last day of nesting; it is less sensitive to unusually early or late nesters as well as to survey omissions. We evaluated the extent to which these phenological metrics changed over this $20 \mathrm{yr}$ period and whether they related to monthly SST measures and nest numbers using linear regression analysis following Weishampel et al. (2004), Pike et al. (2006), and Pike (2009).

\section{RESULTS}

The recent positive and negative nesting trends on these beaches for green turtles and loggerhead turtles, respectively, are evident from the annual tallies (Fig. 2). The average number of loggerhead nests in the $114 \mathrm{~d}$ sampling window was 17117.9 ( $\mathrm{SE}=950.8$ ), while the average number of green turtle nests was 1298.0 ( $\mathrm{SE}=293.9$ ). The proportionately larger standard error for green turtles is, in part, a result of their fairly regular biennial nesting pattern (Fig. 1b); the synchrony in green turtle nesting patterns has been found to relate to SST (Solow et al. 2002).

Contrary to 2 previous, 15 yr studies for loggerheads (Weishampel et al. 2004, Pike et al. 2006), we found no significant phenological trends, i.e. consistent year-toyear increases or decreases, among all the nesting distribution metrics for either turtle species over the $20 \mathrm{yr}$ period. However, there was a relationship between

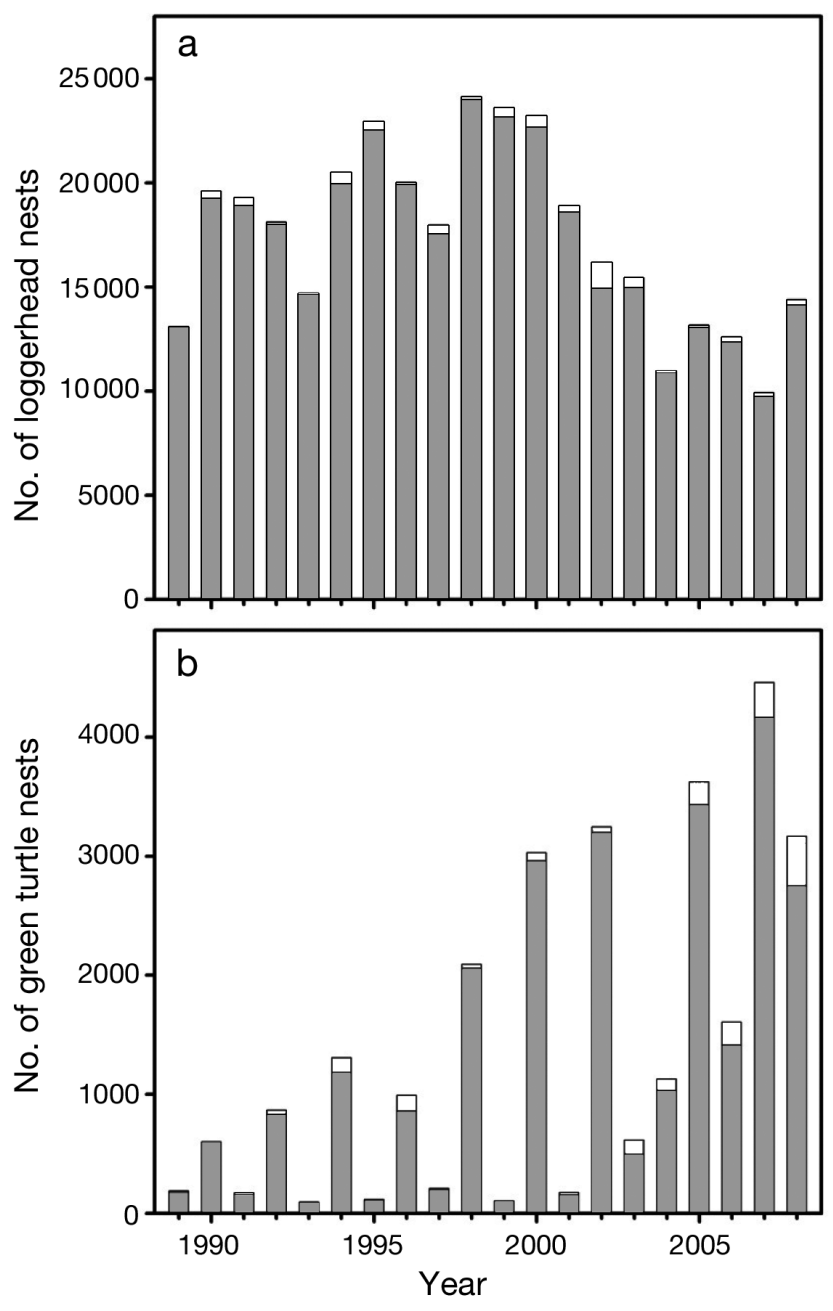

Fig. 2. Caretta caretta and Chelonia mydas. Annual nesting tallies for (a) loggerhead and (b) green turtles from the east central Florida study area from 1989 to 2008. Grey bars are nests that were laid between 10 May and 31 August; white extensions represent nests recorded before 10 May (primarily for loggerheads) and after 31 August (primarily for green turtles) 
May SST and the median ordinal day of nesting for both loggerheads $\left(R^{2}=0.36, p=0.005\right)$ and green turtles $\left(\mathrm{R}^{2}=0.28, \mathrm{p}=0.016\right.$; Fig. 3). As May SST increased, the median days of nesting shifted earlier by $\sim 4.5 \mathrm{~d}$ per ${ }^{\circ} \mathrm{C}$. The average median nesting day for loggerheads and green turtles was 26 June $(\mathrm{SE}=1.11)$ and 25 July $(\mathrm{SE}=1.01)$, respectively, over this $20 \mathrm{yr}$ period. The median dates of nesting for the 2 species were significantly correlated $\left(R^{2}=0.43, p=0.002\right)$.

Similar to the findings of Pike et al. (2006) for the nesting loggerhead turtles at Canaveral National Seashore, which is $\sim 50 \mathrm{~km}$ north of our study area, there was a decrease in the standard deviations of loggerhead nesting distributions associated with increasing daily SST (Fig. 4) averaged across the nesting season, i.e. April through August $\left(\mathrm{R}^{2}=0.27, \mathrm{p}=0.019\right)$.

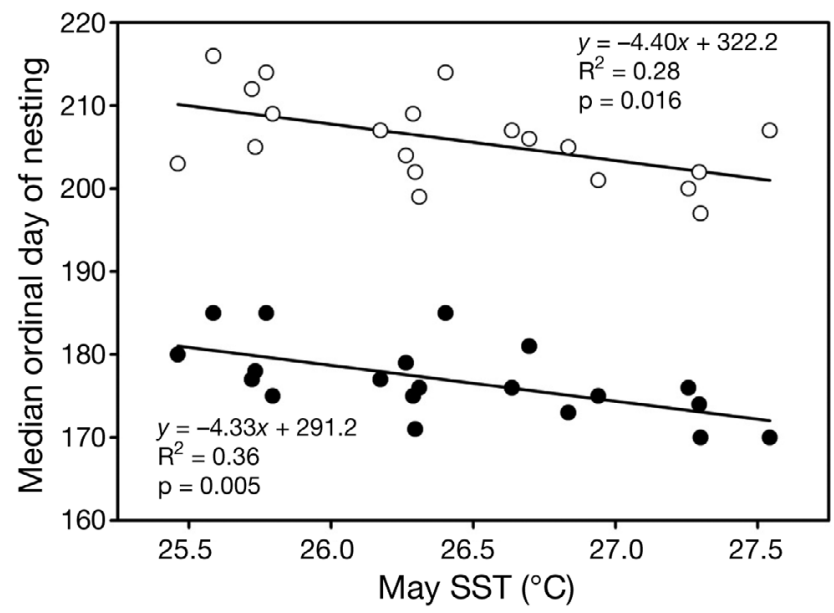

Fig. 3. Caretta caretta and Chelonia mydas. Relationships between average May sea surface temperature (SST) and median ordinal day of nesting for loggerhead $(\bullet)$ and green (O) turtles

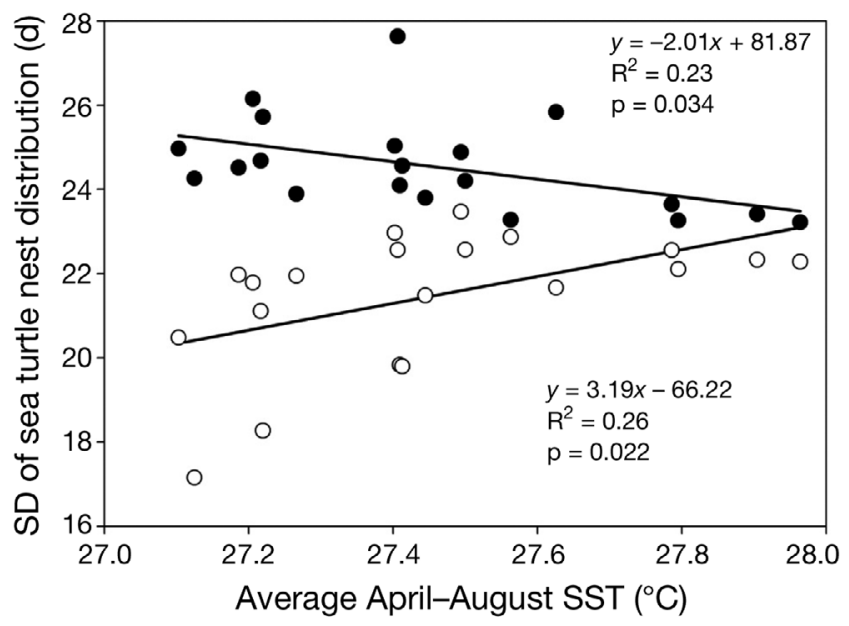

Fig. 4. Caretta caretta and Chelonia mydas. Relationships between average daily sea surface temperature (SST) from April through August and the standard deviations of nest distributions for loggerhead $(\bullet)$ and green $(0)$ turtles
However, the reverse pattern was found with the standard deviations of green turtle nesting distributions, which increased with warmer nesting season SST $\left(\mathrm{R}^{2}=\right.$ $0.20, \mathrm{p}=0.049$ ). The average standard deviation of the distributions for loggerheads was $24.6 \mathrm{~d}(\mathrm{SE}=0.25)$ and for green turtles was $21.5 \mathrm{~d}(\mathrm{SE}=0.36)$. Average standard deviation was significantly, positively correlated with the median day of nesting (Fig. 5) for loggerheads $\left(R^{2}=0.21, p=0.045\right)$ and negatively for green turtles $\left(R^{2}=0.27, p=0.02\right)$. On a monthly basis, the relationship with standard deviation was strongest with July SST for loggerheads ( $\left.R^{2}=0.21, p=0.042\right)$ and with April SST for green turtles $\left(R^{2}=0.55, p<0.001\right)$. There was no significant relation found between number of nests and median date of nesting or standard deviation of nest distribution for either loggerhead or green turtles.

\section{DISCUSSION}

The lack of $20 \mathrm{yr}$ phenological shifts in nesting patterns, which was apparent in the first 15 yr (1989-2003) for loggerheads (Weishampel et al. 2004, Pike et al. 2006), may reflect a recent cooling of the Atlantic Ocean in this region that corresponds to African dust storms (Lau \& Kim 2007). This is shown by the consistently lower May SSTs off the east central Florida coast for 2004-2008 compared to the 2 prior years, 2002 and 2003 (Fig. 6). However, based on the present study, if Caribbean and/or subtropical Atlantic warming over the nesting season does occur, as predicted by climate models (Angeles et al. 2007), both species should respond with earlier nesting and a change in the duration of their nesting seasons.

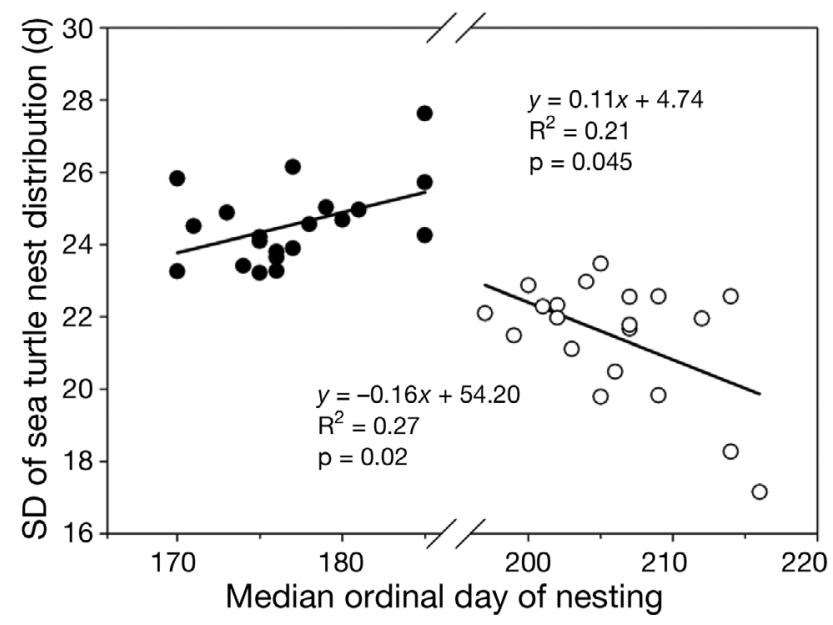

Fig. 5. Caretta caretta and Chelonia mydas. Relationships between median ordinal day of nesting and standard deviations of nest distributions for loggerhead (๑) and green (O) turtles 


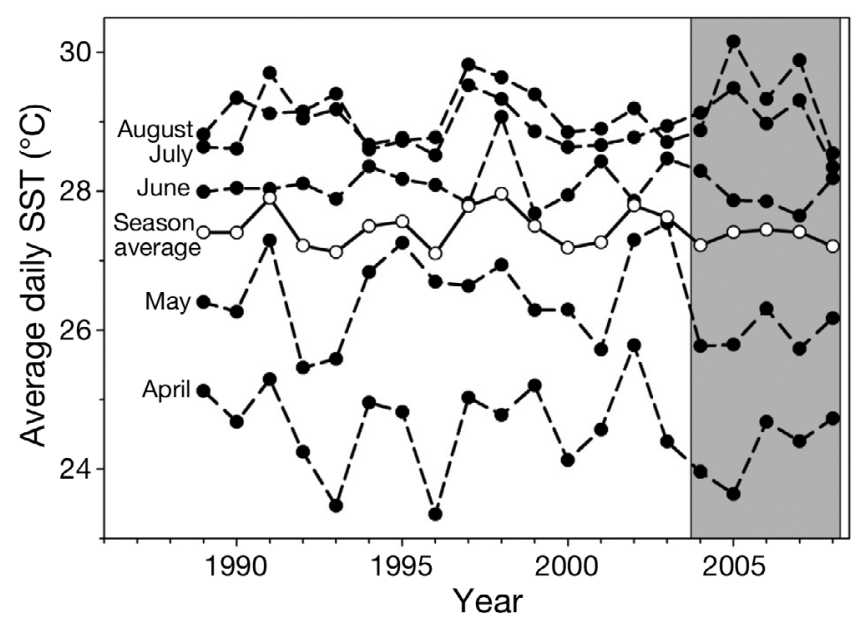

Fig. 6. Twenty-year record of daily sea surface temperature (SST) averaged per month $(\bullet)$ and nesting season average (O) adjacent to the Caretta caretta and Chelonia mydas nesting beaches. Grey window corresponds to the latest $5 \mathrm{yr}$ period which shows a cooling pattern in the early part of the nesting season

Earlier nesting with higher SSTs is consistent with results for Atlantic loggerheads (Weishampel et al. 2004, Pike et al. 2006, Hawkes et al. 2007b). However, our findings with green turtles are in contrast to a recent study from Canaveral National Seashore (Pike 2009), which showed that the timing of green turtle nesting was not significantly ( $p=0.14$ ) related to May SST over the 15 yr study period (1989-2003). The average number of annual green and loggerhead turtle nests in the present 20 yr study (1989-2008), $50 \mathrm{~km}$ to the south, was over 6 times and nearly 5 times, respectively, the average number of nests from the Canaveral study. As found in the present and the Canaveral studies, the slopes of the relationships between May SST and median nesting date for the 2 species show similar trends. Though it is not clear whether the Canaveral loggerhead turtles are genetically distinct from the larger rookery, it appears that there may be haplotype differences between the 2 rookeries for green turtles (B. Shamblin pers. comm.) which may explain differences between the responses. Green turtles at Canaveral nest $\sim 25 \mathrm{~d}$ after those in our study area, which suggests that a comparison with June SST may be more appropriate than May SST. Regardless, the entire population is grouped together as part of the Peninsular Florida Recovery Unit as part of the loggerhead sea turtle population recovery plan (NMFS \& USFWS 2008).

On the stretch of beach analyzed in the present study, loggerhead turtles, on average, nested earlier than green turtles by $\sim 29 \mathrm{~d}$. To the north, at Canaveral National Seashore, loggerhead turtles nested earlier than green turtles by $\sim 20 \mathrm{~d}$. To the south on the Atlantic side of the Florida peninsula, loggerheads nested on average $\sim 30 \mathrm{~d}$ ahead of green turtles. The difference from late June to late July corresponds to roughly a $1^{\circ} \mathrm{C}$ difference in average daily SST for the waters adjacent to the study beaches. The fact that this region corresponds to the northern extent of the green turtle western Atlantic nesting range and the middle of the western North Atlantic nesting range of loggerhead turtles suggests that green turtles are less of a temperate species than loggerheads (see Pritchard 1979) or require more time to assimilate energy necessary to perform reproductive behaviours (Pike 2009) such as migration, courtship, and nesting. Perhaps somewhat counterintuitive, juvenile green turtles exhibit less of a decline in metabolic rate than juvenile loggerhead turtles with decreasing ambient temperatures (Wallace \& Jones 2008). Though there are no comparable metabolic data for adults, this may help explain why the relationship between median nesting date and May SST for green turtles is not as strong as found with loggerhead sea turtles.

As found by Pike et al. (2006) in Florida, but in contrast to the findings of Hawkes et al. (2007b) in North Carolina and Mazaris et al. (2008) in Greece, loggerhead turtle nesting season length, as estimated by the standard deviation of the distribution, decreased with increasing nesting season SST. The North Carolina and Mediterranean rookeries are at the latitudinal northern end of the loggerhead nesting range (CCC 2009). In the present study, the standard deviation of the nest distribution, which we consider a more robust analog for nesting season length, was most closely related to higher July temperatures which are from the latter half of their nesting season (Weishampel et al. 2006). Increased SSTs have been shown to reduce internesting intervals for both species (Sato et al. 1998, Hays et al. 2002). The decrease in season length for loggerheads and the increased season length for green turtles demonstrates that there is a differential response between these sympatric species. The standard deviations of green turtle nesting distributions were significantly correlated with high temperatures early in their nesting season, which suggests that the earlier onset of nesting led to the higher standard deviations. However, it should be noted that after the 31 August survey window used for analysis, proportionately more green turtle nesting has been occurring in recent years (Fig. 2b). The latest recorded nesting event for green turtles, 11 November, was recorded on these beaches in 2006. Green turtles that nest earlier in response to higher SST may be experienced breeders who lay more clutches, as found with earlier nesters in Queensland, Australia (Limpus et al. 2001), which would lead to an increase in nesting season length. Another possible explanation to the increase in nesting season length could relate to an increase in non- 
nesting emergences. In stretches of beaches that underwent restoration after beach erosion, non-nesting emergences increased during the subsequent season (Brock et al. 2009). However, on these beaches, the proportions of non-nesting to nesting emergences for loggerhead and green turtles have been generally steady (Weishampel et al. 2003). Such an increase in nesting season length, in response to higher SST, may make the overall population of green turtle nests less vulnerable to over wash by hurricanes (Pike \& Stiner 2007) by spreading the risk.

Because the 2 turtle species are not known to directly influence one another, the difference in their phenological response probably does not have ramifications, such as intraspecific competition for nest space (e.g. Jessop \& Hamann 2004), for the populations associated with these beaches. Their differential response, in terms of the standard deviation of the nesting season, is of interest and may reflect differences in their diet - green turtles are herbivores (Bjorndal 1995) and loggerheads are primarily carnivores (Dodd 1988, Pike 2009) - or the general plasticity of reproductive physiologies. Green turtles have been shown to have greater variation in clutch frequency than loggerhead turtles at the same nesting site (Broderick et al. 2001). However, an increase in the nesting season length for green turtles, if it is associated with increased clutch numbers (Limpus et al. 2001), could represent changes in the timing, duration of availability, and/or quality of their food sources (e.g. Edwards \& Richardson 2004). The food sources differ for the 2 species and should relate to SST in their foraging areas (Chaloupka et al. 2008b) perhaps more than 1 yr prior to nesting (Limpus $\&$ Nicholls 1988). To assess this adequately will require consistent, longer-term monitoring of foraging and nesting and/or new statistical modeling (Girondot et al. 2006) approaches following SSTs along the turtles' migratory paths. Given the general predicted warming of SST for this region, coastal managers of these beaches may need to adjust their monitoring and/or management activities (e.g. Jackson et al. 2008) to accommodate earlier loggerhead turtle nesting and longer green turtle nesting seasons. However, with intra- and interannual SST and nesting variability along the Atlantic and Gulf of Mexico coasts, larger regional analyses of phenology across the nesting ranges of these species is warranted to identify broader behavioural patterns and population implications.

Acknowledgements. We kindly thank the UCF Marine Turtle Research Group, which has received funding over the years from a variety of sources. Recent beach survey efforts have been supported by the US Fish and Wildlife Service and the Brevard County Office of Natural Resource Management. We also appreciate D. A. Pike and L. A. Hawkes for supplying us with preprints of their related research and the comments from S. Ceriani, A. Hays, T. Long, D. A. Pike, A. Sterner, and 2 anonymous reviewers. This long-term research program is permitted jointly by the Florida Fish and Wildlife Conservation Commission and the US Fish and Wildlife Service and was approved by the animal care committee at UCF.

\section{LITERATURE CITED}

Angeles ME, Gonzalez JE, Erickson DJ, Hernández JL (2007) Predictions of future climate change in the Caribbean region using global circulation models. Int J Climatol 27: 555-569

Bjorndal KA (1995) The consequences of herbivory for the life history pattern of the Caribbean green turtle, Chelonia mydas. In: Bjorndal KA (ed) Biology and conservation of sea turtles. Smithsonian Institution Press, Washington, DC, p 111-116

> Bonnet X, Bradshaw D, Shine R (1998) Capital versus income breeding: an ectothermic perspective. Oikos 83:333-342

> Brock KA, Reece JS, Ehrhart LM (2009) The effects of artificial beach nourishment on marine turtles: difference between loggerhead and green turtles. Restor Ecol 17: 297-307

Broderick AC, Godley BJ, Hays GC (2001) Trophic status drives interannual variability in nesting numbers of marine turtles. Proc R Soc Lond B 268:1481-1487

CCC (Caribbean Conservation Corporation) (2009) Species fact sheet: green sea turtle. CCC, Gainesville, FL, available at www.cccturtle.org/seaturtleinformation.php?page =green (accessed 30 September 2009)

Chaloupka M, Bjorndal KA, Balazs GH, Bolten AB and others (2008a) Encouraging outlook for recovery of a once severely exploited marine megaherbivore. Global Ecol Biogeogr 17:297-304

Chaloupka M, Kamezaki N, Limpus C (2008b) Is climate change affecting the population dynamics of the endangered Pacific loggerhead sea turtle? J Exp Mar Biol Ecol 356:136-143

Cheng IJ, Huang CT, Hung PY, Ke BZ, Kuo CW, Fong CL (2009) Ten years of monitoring the nesting ecology of the green turtle, Chelonia mydas, on Lanyu (Orchid Island), Taiwan. Zool Stud 48:83-94

> Coles WC, Musick JA (2000) Satellite sea surface temperature analysis and correlation with sea turtle distribution off North Carolina. Copeia 2000:551-554

Cross CL, Gallegos JB, James FG (2001) Loggerhead sea turtle late nesting ecology in Virginia Beach, Virginia. Banisteria 17:52-55

Dodd KC Jr (1988) Synopsis of the biological data on the loggerhead sea turtle Caretta caretta (Linnaeus 1758). US Fish Wildl Serv Biol Rep 88:1-119

Edwards M, Richardson AJ (2004) Impact of climate change on marine pelagic phenology and trophic mismatch. Nature 430:881-884

Ehrhart LM, Bagley DA, Redfoot WE (2003) Loggerhead turtles in the Atlantic Ocean: geographic distribution, abundance, and population status. In: Bolton $A B$, Witherington BE (eds) Loggerhead sea turtles. Smithsonian Institution Press, Washington, DC, p 157-174

FWRI (Fish and Wildlife Research Institute) (2009) Index nesting beach survey (INBS) protocol. FWRI, St. Petersburg, FL, available at http://research.myfwc.com/images/articles/31770/inbs_protocol.pdf (accessed 5 May 2009)

> Girondot M, Rivalan P, Wongsopawiro R, Briane JP, Hulin V, Caut S, Guirlet E, Godfrey MH (2006) Phenology of 
marine turtle nesting revealed by statistical model of the nesting season. BMC Ecol 6:11

Godley BJ, Thompson DR, Waldron S, Furness RW (1998) The trophic status of marine turtles as determined by stable isotope analysis. Mar Ecol Prog Ser 166:277-284

Hamann M, Limpus CJ, Owens DW (2003) Reproductive cycles of males and females. In: Lutz PL, Musick JA, Wyneken J (eds) The biology of sea turtles, Vol II. CRC Press, Boca Raton, FL, p 135-161

Hawkes LA, Broderick AC, Coyne MS, Godfrey MH, Godley BJ (2007a) Only some like it hot-quantifying the environmental niche of the loggerhead sea turtle. Divers Distrib 13:447-457

> Hawkes LA, Broderick AC, Godfrey MH, Godley GJ (2007b) Investigating the potential impacts of climate change on a marine turtle population. Global Change Biol 13:923-932

Hawkes LA, Broderick AC, Godfrey MH, Godley GJ (2009) Climate change and marine turtles. Endang Species Res $7: 137-154$

Hays GC, Broderick AC, Glen G, Godley BJ, Houghton JDR, Metcalfe JD (2002) Water temperature and internesting intervals for loggerhead (Caretta caretta) and green (Chelonia mydas) sea turtles. J Therm Biol 27:429-432

- Jackson AL, Broderick AC, Fuller WJ, Glen F, Ruxton GD, Godley BJ (2008) Sampling design and its effect on population monitoring: How much monitoring do turtles really need? Biol Conserv 141:2932-2941

Jessop TS, Hamann M (2004) Hormonal and metabolic responses to nesting activities in the green turtle, Chelonia mydas. J Exp Mar Biol Ecol 308:253-267

Lau KM, Kim KM (2007) Cooling of the Atlantic by Saharan dust. Geophys Res Lett 34:L23811

Limpus CJ, Nicholls N (1988) The Southern Oscillation regulates the annual numbers of green turtles (Chelonia mydas) breeding around northern Australia. Aust Wildl Res 15:157-162

Limpus CJ, Carter D, Hamann M (2001) The green turtle, Chelonia mydas, in Queensland, Australia: the Bramble Cay Rookery in the 1979-1980 breeding season. Chelonian Conserv Biol 4:34-46

Mazaris AD, Kornaraki E, Matsinos YG, Margaritoulis D (2004) Modeling the effect of sea surface temperature on sea turtle nesting activities by investigating seasonal trends. Nat Resour Model 17:445-465

Mazaris AD, Kallimanis AS, Sgardelis SP, Pantis JD (2008) Do long-term changes in sea surface temperature at the breeding areas affect the breeding dates and reproductive performance of Mediterranean loggerhead turtles? Implications for climate change. J Exp Mar Biol Ecol 367: 219-226

NMFS (National Marine Fisheries Service), USFWS (US Fish and Wildlife Service) (2008) Recovery plan for the Northwest Atlantic population of the loggerhead sea turtle (Caretta caretta), 2nd revision. NMFS, Silver Spring, MD

Parmesan C (2006) Ecological and evolutionary responses to recent climate change. Annu Rev Ecol Evol Syst 37: 637-669

Pike DA (2009) Do green turtles modify their nesting seasons in response to environmental temperatures? Chelonian Conserv Biol 8:43-47

Pike DA, Stiner JC (2007) Sea turtle species vary in their sus-

Editorial responsibility: Matthew Godfrey,

Beaufort, North Carolina, USA ceptibility to tropical cyclones. Oecologia 153:471-478

Pike DA, Antworth RL, Stiner JC (2006) Earlier nesting contributes to shorter nesting seasons for the loggerhead seaturtle, Caretta caretta. J Herpetol 40:91-94

Poloczanska ES, Limpus CJ, Hays GC (2009) Vulnerability of marine turtles to climate change. Adv Mar Biol 56: $151-211$

Pritchard PCH (1979) Encyclopedia of turtles. T. F. H. Publications, Neptune, NJ

Reynolds RW, Smith TM (1994) Improved global sea surface temperature using optimum interpolation. J Clim 7: 929-948

> Sato K, Matsuzawa Y, Tanaka H, Bando T, Minamikawa S, Sakamoto W, Naito Y (1998) Internesting intervals for loggerhead turtles, Caretta caretta, and green turtles, Chelonia mydas, are affected by temperature. Can J Zool 76: 1651-1662

Schofield G, Bishop CM, Katselidis KA, Dimopoulos P, Pantis JD, Hays GC (2009) Microhabitat selection by sea turtles in a dynamic thermal marine environment. J Anim Ecol 78: $14-21$

Schwartz FJ, Peterson C, Passingham H, Fridell J, Wooten J (1981) First successful nesting of the green turtle, Chelonia mydas, in North Carolina and North of Georgia. ASB Bull 28:96

Seminoff JA, Zárate P, Coyne M, Foley DG, Parker D, Lyon BN, Durron PH (2008) Post-nesting migrations of Galápagos green turtles Chelonia mydas in relation to oceanographic conditions: integrating satellite telemetry with remotely sensed ocean data. Endang Species Res 4:57-72

Solow AR, Bjorndal KA, Bolten AB (2002) Annual variation in nesting numbers of marine turtles: the effect of sea surface temperature on re-migration intervals. Ecol Lett 5: 742-746

USFWS (US Fish and Wildlife Service) (2009) Archie Carr National Wildlife Refuge. USFWS, Vero Beach, FL, available at www.fws.gov/archiecarr (accessed 21 April 2010)

Visser ME, Both C (2005) Shifts in phenology due to global climate change: the need for a yardstick. Proc R Soc Lond B 272:2561-2569

Wallace BP, Jones TT (2008) What makes marine turtles go: a review of metabolic rates and their consequences. J Exp Mar Biol Ecol 356:8-24

Weishampel JF, Bagley DA, Ehrhart LM, Rodenbeck BL (2003) Spatiotemporal patterns of annual sea turtle nesting behaviors along an east central Florida beach. Biol Conserv 110:295-303

> Weishampel JF, Bagley DA, Ehrhart LM (2004) Earlier nesting by loggerhead sea turtles following sea surface warming. Global Change Biol 10:1424-1427

Weishampel JF, Bagley DA, Ehrhart LM (2006) Intra-annual loggerhead and green turtle spatial nesting patterns. Southeast Nat 5:453-462

Williams SE, Shoo LP, Isaac JL, Hoffman AA, Langham G (2008) Towards an integrated framework for assessing the vulnerability of species to climate change. PLoS Biol 6: e325

Witherington B, Kubilis P, Brost B, Meylan A (2009) Decreasing annual nest counts in a globally important loggerhead sea turtle population. Ecol Appl 19:30-54

Woodson HM, Webster WD (1999) Chelonia mydas (green sea turtle) nesting distribution. Herpetol Rev 34:224-225

Submitted: May 28, 2009; Accepted: May 7, 2010

Proofs received from author(s): May 27, 2010 